\title{
$L 655,240$, acting as a competitive BACE1 inhibitor, efficiently decreases $\beta$-amyloid peptide production in HEK293-APPswe cells
}

\author{
Qin $\mathrm{LU}^{1}$, Wu-yan $\mathrm{CHEN}^{2}$, Zhi-yuan ZHU², Jing $\mathrm{CHEN}^{2}$, Ye-chun $\mathrm{XU}^{2}$, Morakot KAEWPET ${ }^{3}$, Vatcharin RUKACHAISIRIKUL ${ }^{3}$, \\ Li-li CHEN ${ }^{2, *}$, Xu SHEN $^{1,2, *}$ \\ ${ }^{1}$ School of Pharmacy, East China University of Science and Technology, Shanghai 200237, China; ${ }^{2}$ State Key Laboratory of Drug \\ Research, Shanghai Institute of Materia Medica, Chinese Academy of Sciences, Shanghai 201203, China; ${ }^{3}$ Department of Chemistry \\ and Center for Innovation in Chemistry, Faculty of Science, Prince of Songkla University, Thailand
}

\begin{abstract}
Aim: To identify a small molecule L655,240 as a novel $\beta$-secretase (BACE1) inhibitor and to investigate its effects on $\beta$-amyloid (A $\beta$ ) generation in vitro.

Methods: Fluorescence resonance energy transfer (FRET) was used to characterize the inhibitory effect of L655,240 on BACE1. Surface plasmon resonance (SPR) technology-based assay was performed to study the binding affinity of L655,240 for BACE1. The selectivity of L655,240 toward BACE1 over other aspartic proteases was determined with enzymatic assay. The effects of L655,240 on A $440, A \beta 42$, and SAPP $\beta$ production were studied in HEK293 cells stably expressing APP695 Swedish mutant ${ }^{\mathrm{K} 595 \mathrm{~N} / \mathrm{M} 596 \mathrm{~L}}$ (HEK293APPswe cells). The activities of BACE1, $\gamma$-secretase and $\alpha$-secretase were assayed, and both the mRNA and protein levels of APP and BACE1 were evaluated using real-time PCR (RT-PCR) and Western blot analysis.

Results: L655,240 was determined to be a competitive, selective BACE1 inhibitor $\left(\mathrm{IC}_{50}=4.47 \pm 1.37 \mu \mathrm{mol} / \mathrm{L}\right)$, which bound to BACE1 directly $\left(K_{D}=17.9 \pm 0.72 \mu \mathrm{mol} / \mathrm{L}\right)$. L655,240 effectively reduced A 40, Aß42, and SAPP $\beta$ production by inhibiting BACE1 without affecting the activities of $\gamma$-secretase and $\alpha$-secretase in HEK293-APPswe cells. L655,240 has no effect on APP and BACE1 mRNA or protein levels in HEK293-APPswe cells.

Conclusion: The small molecule L655,240 is a novel BACE1 inhibitor that can effectively decreases A $\beta$ production in vitro, thereby highlighting its therapeutic potential for the treatment of Alzheimer's disease.
\end{abstract}

Keywords: L655,240; Alzheimer's disease; BACE1; $\beta$-amyloid peptide; HEK293-APPswe cells

Acta Pharmacologica Sinica (2012) 33: 1459-1468; doi: 10.1038/aps.2012.74; published online 30 Jul 2012

\section{Introduction}

Alzheimer's disease (AD) is a progressive neurodegenerative disorder that is characterized by cognitive impairment and memory dysfunction. The elderly are at high risk for developing AD, especially those aged 65 years and older ${ }^{[1]}$. The incidence of AD is expected to rise as the aging population grows and to create an increasingly heavy burden for families and society. To date, several therapeutic strategies have been identified to treat AD. For example, acetylcholinesterase inhibitors (AChEIs), N-methyl-D-aspartate (NMDA) antagonists, antihypertensive drugs and anti-inflammatory drugs $^{[2]}$ have been reported to be effective in combating AD.

\footnotetext{
* To whom correspondence should be addressed.

E-mail xshen@mail.shcnc.ac.cn (Xu SHEN); lilichen@mail.shcnc.ac.cn (Li-li CHEN)

Received 2012-03-02 Accepted 2012-05-16
}

However, only AChEIs (eg, donepezil, galantamine, tacrine and rivastigmine $)^{[3]}$ and one NMDA antagonist (memantine) $)^{[4]}$ have been approved by the Food and Drug Administration (FDA) to treat AD. These drugs also have several limitations, including short half-lives, considerable side effects and high costs. Some antihypertensive drugs, such as angiotensin converting enzyme (ACE) inhibitors ${ }^{[5]}$, calcium channel blockers ${ }^{[6]}$ and nonsteroidal anti-inflammatory drugs (NSAIDs) ${ }^{[7]}$, have also been shown to reduce mental decline in AD patients or to decrease the risk of acquiring AD. However, they have not been used for AD treatment. Because secretase $[\beta$-secretase (beta-site APP-cleaving enzyme 1, BACE1) and $\gamma$-secretase] inhibitors can reduce $A \beta$ production and no secretase inhibitors are currently marketed to treat AD, the development of BACE1 inhibitors offers a potentially powerful clinical option for AD therapy.

The factors that have most commonly been suggested to 
cause AD are intracellular neurofibrillary tangles composed of a hyperphosphorylated form of the microtubule-associated protein tau and extracellular neuritic plaques aggregated by $\beta$-amyloid $(A \beta)$ peptides $(A \beta 40 \text { and } A \beta 42)^{[8,9]}$. The membranespanning amyloid precursor protein (APP) is sequentially cleaved into A $\beta$ by BACE1 and $\gamma$-secretase. BACE1 initially cleaves APP at the N-terminus, yielding the soluble APP $\beta$ (sAPP $\beta$ ) and the C-terminal, membrane-bound stub of 99 amino acids (C99). C99 is further cleaved by $\gamma$-secretase to generate $A \beta(A \beta 40$ and $A \beta 42)$ and the amyloid intracellular domain $(\mathrm{AICD})^{[1,10]}$.

As mentioned, both BACE1 and $\gamma$-secretase play essential roles in $A \beta$ production. Previous results have indicated that knocking out the BACE1 gene abrogates pathogenic $A \beta$ production in mice and that this gene ablation rescues memory deficits and cholinergic dysfunction in APP transgenic mice $^{[11-13]}$. Similarly, mice with a BACE1 gene deletion remain healthy, fertile and viable, except for partial hypomyelination at the juvenile development stage ${ }^{[14-16]}$. However, previous reports have revealed that $\gamma$-secretase can cleave not only APP but also Notch (an essential protein for proper formation of the axial skeleton, normal neurogenesis and neuronal survival in the embryo ${ }^{[17-19]}$, and the absence of the catalytic subunits of $\gamma$-secretase (presenilin 1 and 2) is known to cause embryonic lethality due to the disruption of Notch. Therefore, BACE1 has been suggested to be a more attractive therapeutic target than $\gamma$-secretase for the treatment or prevention of AD.

Because BACE1 is a rate-limiting enzyme during $A \beta$ secretion, many research groups have focused on the identification of BACE1 inhibitors. The first class of BACE1 inhibitors was designed based on the specificity of BACE1 cleavage of APP, an example of which is the first-generation inhibitor OM99-2, an eight-residue peptide ${ }^{[20]}$. Although the bulky structure of this inhibitor has prevented its application in vivo, the BACE1/ OM99-2 co-crystal structure has provided vivid molecular insight into the interaction of BACE1 with the ligand, paving the way for design of later BACE1 inhibitors ${ }^{[20]}$. Subsequently, some penta-peptidic BACE1 inhibitors, such as KMI-429, KMI570 and KMI-684 were reported to significantly decrease $A \beta$ production when directly injected into the hippocampus of APP transgenic mice ${ }^{[21,22]}$. In addition to these compounds designed based on the substrate, small molecular non-peptidic compounds, including GSK188909 $9^{[23]}$, compound $\mathbf{1 1}^{[24]}$ and CTS-21166 $6^{[25]}$, were reported to be highly effective in reducing $A \beta$ production when administered orally to APP/PS1 transgenic mice. Of these substrate-based BACE1 inhibitors, CTS-21166 has passed Phase 1 clinical trials ${ }^{[25]}$. Another class of non-peptidic BACE1 inhibitors were obtained from a highthroughput screening (HTS) technology-based assay targeting chemical libraries. Typical examples of this class of inhibitors include compounds $\mathbf{1 0 d ^ { [ 2 6 ] }}, \mathbf{3} \mathbf{a}^{[27]}$, and TAK- $070^{[28]}$, which are orally active and show good selectivity over other aspartic proteases. The third class of BACE1 inhibitors includes natural products, such as catechins obtained from Green tea ${ }^{[22]}$, lavandulyl flavanones extracted from Sophora flavescens ${ }^{[30]}$, resveratrol obtained from Vitis vinifera ${ }^{[31]}$ and TDC obtained from

\section{Glycyrrhiza glabra ${ }^{[32]}$.}

Currently, significant research efforts have been undertaken to find small molecule BACE1 inhibitors with satisfactory pharmacological properties. However, due to the difficulty in developing drugs that can efficiently cross the blood-brain barrier and reach appropriate therapeutic concentrations in the cerebral parenchyma without causing other side effects, no BACE1 inhibitor has yet been marketed to treat AD, although some inhibitors have passed Phase 1 clinical trials. Therefore, the discovery of new BACE 1 inhibitors remains highly significant.

In the current study, we identified a new type of BACE1 inhibitor, L655,240 (Figure 1). L655,240 was previously reported to be a potent, orally active thromboxane/prostaglandin endoperoxide antagonist ${ }^{[33]}$, which significantly attenuated Sephadex-induced bronchial hyper-responsiveness ${ }^{[34]}$ and protected against reperfusion-induced ventricular fibrillation and early (Phase 1a) ischemia-induced arrhythmias ${ }^{[35]}$. Here, we report a novel biological role for L655,240 as a potential BACE1 inhibitor. Our work provides novel structural information for the development of potential AD drug lead compounds in the future.

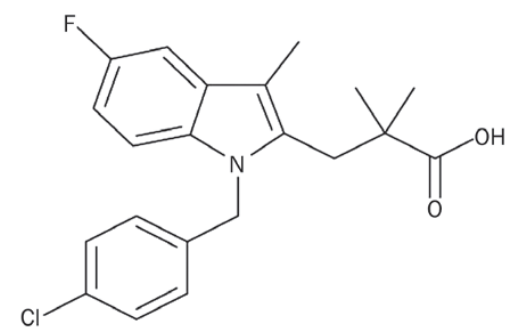

Figure 1. Chemical structure of L655,240 (1-[(4-chlorophenyl)methyl]-5fluoro- $\alpha, \alpha, 3$-trimethyl- $1 H$-indole-2-propanoic acid).

\section{Materials and methods Materials}

L655,240 was purchased from Enzo Life Sciences (Farmingdale, NY, USA). All cell culture regents were obtained from Gibco (Rockville, MD, USA). The BACE1 FRET assay kit, human A $\beta 40$ ELISA kit, human A $\beta 42$ ELISA kit and the Rh-EVNLDAEFK-Quencher substrate were from Invitrogen (Carlsbad, CA, USA). Black 384-well microplates were obtained from Greiner Bio-One $\mathrm{GmbH}$ (Frickenhausen, Germany). GAPDH antibody was from Kangchen (Shanghai, China). APP antibody and the human sAPP $\beta$ (highly sensitive) assay kit were purchased from Immuno-Biological Laboratories (IBL) (Takasaki-Shi, Gunma, Japan). BACE1 antibody, MTT (3-(4,5-dimethylthiazol-2-yl)-2,5-diphenyltetrazolium bromide), Geneticin (G418), and complete protease inhibitor cocktail were from Sigma-Aldrich (St Louis, MO, USA). Cathepsin D from human liver was from Merck (Darmstadt, Germany). Renin activity assay kits were from Anaspec (Fremont, CA, USA). RIPA buffer, Pierce BCA Protein Assay kits 
and SuperSignal West Dura chemiluminescence kits were obtained from Thermo Scientific (Rockford, IL, USA). RNAiso, PrimeScript $^{\mathrm{TM}}$ RT reagent kits and SYBR Premix Ex Taq were purchased from Takara (Otsu, Shiga, Japan). Anti-rabbit IgG and anti-mouse IgG were from Jackson ImmunoResearch (West Grove, PA, USA). Hybond-C nitrocellulose membranes for Western blot experiments were obtained from GE Healthcare (Uppsala, Sweden).

\section{Protein expression and purification}

BACE1 expression, refolding and purification were performed as previously reported ${ }^{[36]}$. Briefly, a BACE1 cDNA fragment encoding residues 43 to 454 was cloned into a pET28a vector with a six-residue His tag at the N-terminus. The pET28aBACE1 plasmid was transfected into Escherichia coli (E coli) cells, and BACE1 was expressed in inclusion bodies, then denatured and refolded into the active monomeric form.

\section{BACE1 activity assay}

BACE1 enzyme activity was assayed by measuring the cleavage of the FRET substrate, Rh-EVNLDAEFK-Quencher, which was designed based on the APP695 Swedish mutant ${ }^{\text {K595N/M596L }}$. The assay was performed in a $50 \mathrm{mmol} / \mathrm{L}$ sodium acetate reaction buffer at $\mathrm{pH} 4.5$. BACE1 enzyme was diluted in the reaction buffer to make a $3 \times$ working solution (the concentration of BACE1 enzyme purchased from Invitrogen was $1.56 \mu \mathrm{g} / \mathrm{mL}$; the concentration of BACE1 enzyme purified from $E$ coli was 2 $\mu \mathrm{g} / \mathrm{mL})$. BACE1 substrate was diluted in the reaction buffer to make a $3 \times$ stock solution $(750 \mathrm{nmol} / \mathrm{L})$. L655,240 was also diluted to various concentrations to make $3 \times$ working solutions. The assay was performed in black 384-well microplates in a final volume of $30 \mu \mathrm{L}$ containing $10 \mu \mathrm{L}$ of $3 \times$ substrate stock, $10 \mu \mathrm{L}$ of $3 \times$ BACE1 working solution and $10 \mu \mathrm{L}$ of various concentrations of L655,240. The reaction mixture was incubated at $37^{\circ} \mathrm{C}$ for 90 min with vehicle (dimethyl sulfoxide, DMSO) at a final concentration of $1 \%(v / v)$. After incubation, $10 \mu \mathrm{L}$ of stop solution $(2.5 \mathrm{~mol} / \mathrm{L}$ sodium acetate) was added to stop the reaction. Finally, the fluorescence intensity of the enzymatic product was measured at $E x / E m=535 \mathrm{~nm} / 585 \mathrm{~nm}$ on a TECAN GENios reader (Tecan, Männedorf, Switzerland).

To determine the inhibitory type, double-reciprocal (Lineweaver-Burk) plot analysis was performed using a series of concentrations of L655,240 (final concentrations of 0,2 , and 5 $\mu \mathrm{mol} / \mathrm{L}$ ) and of substrate (final concentrations of $0,62.5,125$, 250, 500, and $1000 \mathrm{nmol} / \mathrm{L})$. Substrate was added to BACE1 mixed with vehicle or L655,240 to start the kinetic reaction, and the fluorescence intensity was measured immediately at $\mathrm{Ex} / \mathrm{Em}=535 \mathrm{~nm} / 585 \mathrm{~nm}$. Data were recorded continuously every $1 \mathrm{~min}$ for $90 \mathrm{~min}$. Finally, the initial velocity of the enzyme reaction was obtained by determining the slope of the linear portion of the data plot.

To evaluate the inhibitory effect of L655,240 on BACE1 activity in cells, a series of concentrations of L655,240 were incubated with cultured cells for $24 \mathrm{~h}$ until cells reached confluence in six-well plates. After incubation, the cultures were removed, and the cells were washed with ice cold PBS. Next,
$150 \mu \mathrm{L}$ of RIPA buffer containing $1 \%(v / v)$ complete protease inhibitor cocktail was added, and the samples were incubated for $30 \mathrm{~min}$ on ice. The samples were finally centrifuged at $20000 \times g$ at $4{ }^{\circ} \mathrm{C}$. The supernatant was collected and stored at $-80{ }^{\circ} \mathrm{C}$ until later use. Total protein levels were determined using the BCA Protein Assay Reagent kit. The BACE1 activity of the cell lysates was assayed according to the methods described above.

\section{Renin and cathepsin D activity assays}

The activity and inhibition of renin by L655,240 were assayed according to the manufacturer's instructions using a renin activity assay kit. The activity of cathepsin $\mathrm{D}$ derived from the human liver and inhibition of cathepsin D activity by L655,240 was determined using Rh-EVNLDAEFK-Quencher as the substrate. Briefly, a series of concentrations of L655,240 was incubated with $250 \mathrm{nmol} / \mathrm{L}$ Rh-EVNLDAEFK-Quencher substrate and $0.02 \mathrm{unit} / \mathrm{mL}$ cathepsin $\mathrm{D}$ in reaction buffer $(50 \mathrm{mmol} / \mathrm{L}$ sodium acetate, $\mathrm{pH} 4.5$ ) for $1 \mathrm{~h}$. Then, the fluorescence intensity of the enzymatic products was measured at $\mathrm{Ex} / \mathrm{Em}=535$ $\mathrm{nm} / 585 \mathrm{~nm}$.

\section{Surface plasmon resonance (SPR) technology-based assay}

The potential for direct binding of L655,240 to BACE1 was investigated using a fully automated SPR-based Biacore 3000 instrument. During the experiment, BACE1 purified from $E$ coli was immobilized on a CM5 sensor chip according to the Biacore manual. L655,240 was serially diluted with HBS buffer [10 mmol/L HEPES, $150 \mathrm{mmol} / \mathrm{L} \mathrm{NaCl}, 3 \mathrm{mmol} / \mathrm{L}$ EDTA and $0.05 \%(v / v)$ surfactant P20] to a final concentration of $0.1 \%$ DMSO $(v / v)$. The samples were injected into the channels at a flow rate of $30 \mu \mathrm{L} / \mathrm{min}$ and then washed with HBS buffer. The binding RU (Response Unit) values of L655,240 to BACE1 were recorded directly by the Biacore 3000 instrument and calculated by subtracting the signal from the vehicle $(0.1 \%$ DMSO).

\section{Cell culture and inhibitor treatment}

HEK293 cells were purchased from the American Type Culture Collection (ATCC) and cultured in Dulbecco's modified Eagle's medium (DMEM) supplemented with 10\% $(v / v)$ fetal bovine serum (FBS), $100 \mathrm{unit} / \mathrm{mL}$ penicillin and $100 \mu \mathrm{g} / \mathrm{mL}$ streptomycin at $37^{\circ} \mathrm{C}$ in $5 \% \mathrm{CO}_{2}$. HEK293-APPswe cells were grown in the same culture medium, with the addition of 1 $\mathrm{mg} / \mathrm{mL}$ geneticin (G418).

\section{Quantitation of $A \beta$ and SAPP $\beta$}

HEK293-APPswe cells were seeded into 6-well plates. When cells reached $80 \%$ confluence, cultures were refreshed with DMEM supplemented with the indicated concentrations of L655,240 for an additional $24 \mathrm{~h}$. To determine the levels of $\mathrm{A} \beta 40, \mathrm{~A} \beta 42$, and $\mathrm{sAPP} \beta$ secreted in the medium, the medium was directly collected from the plates, and a complete protease inhibitor cocktail was added to a final concentration of $1 \%(v / v)$. Then, the medium was centrifuged at $20000 \times g$ at $4^{\circ} \mathrm{C}$ for $5 \mathrm{~min}$, and the supernatant was collected for $\mathrm{A} \beta 40$, 
$A \beta 42$ and sAPP $\beta$ quantitation. To measure sAPP $\beta$ levels, the supernatant was diluted 1:100 with the standard dilution buffer from the sAPP $\beta$ ELISA kit and assayed according to the kit protocol. For quantitation of $A \beta 40$ and $A \beta 42$, the supernatant was directly assayed without dilution.

To quantify intracellular $\mathrm{A} \beta 40, \mathrm{~A} \beta 42$, and $\mathrm{sAPP} \beta$ levels in cells, the cells were lysed as described above. To detect the contents of $A \beta 40$ and $A \beta 42$ in the cell lysates, the samples were diluted 1:2 in the standard dilution buffer from the human $A \beta 40$ and $A \beta 42$ kits, respectively. For sAPP $\beta$ quantitation, the samples were diluted 1:10 in the standard dilution buffer from the human sAPP $\beta$ ELISA kit.

\section{Cell viability assay}

HEK293-APPswe cells were seeded into 48-well plates at a density of $20 \%$ per well. After culturing for $12 \mathrm{~h}$, the cells were treated with different concentrations of L655,240 or vehicle (DMSO) for $24 \mathrm{~h}$. Subsequently, the medium containing L655,240 or vehicle was replaced with fresh medium supplemented with $0.5 \mathrm{mg} / \mathrm{mL}$ MTT in the absence of L655,240 or vehicle, and the cells were cultured for an additional $4 \mathrm{~h}$. Finally, the medium was discarded, and $300 \mu \mathrm{L}$ of DMSO was added to each well. After incubation with DMSO for $10 \mathrm{~min}$, the absorption intensities of the samples were measured at 490 nm.

\section{Western blot analysis}

HEK293 and HEK293-APPswe cells treated with L655,240 or vehicle for $24 \mathrm{~h}$ were harvested in $2 \times$ sodium dodecyl sulfatepolyacrylamide gel electrophoresis (SDS-PAGE) sample buffer (25\% SDS, 62.5 mmol/L Tris- $\mathrm{HCl}, \mathrm{pH}$ 6.8, 25\% glycerol, and $0.1 \%$ bromophenol blue). The samples were resolved on $10 \%$ SDS-PAGE or $8 \%$ SDS-PAGE gels and transferred to Hybond-C nitrocellulose membranes. The membranes were blocked in 5\% milk for $20 \mathrm{~min}$ and then incubated overnight at $4{ }^{\circ} \mathrm{C}$ with the corresponding primary antibody. On the next day, the membranes were washed 3 times for 45 min with TBST buffer $(20 \mathrm{mmol} / \mathrm{L}$ Tris-HCl, pH 7.4, $140 \mathrm{mmol} / \mathrm{L} \mathrm{NaCl}$, $0.5 \%$ Tween-20) and then incubated in 5\% milk (v/v) supplemented with anti-rabbit IgG or anti-mouse IgG for $2 \mathrm{~h}$ at room temperature. After incubating with the secondary antibody, the membranes were washed 3 times for 45 min with TBST buffer. Finally, blots were visualized by incubation with a SuperSignal West Dura chemiluminescence kit (Pierce Biotechnology, Rockford, IL, USA), and images were acquired using an ImageQuant LAS 4000 mini (GE Healthcare Life Sciences, CT, USA). GAPDH was used as a reference control for protein loading. The bands were quantified using ImageQuant TL 7.0 software.

\section{Real-time PCR (RT-PCR) analysis}

Total RNA was extracted using an RNAiso reagent kit, and complementary cDNA synthesis was performed using a PrimeScript ${ }^{\mathrm{TM}} \mathrm{RT}$ reagent $\mathrm{kit}^{[37]}$. RT-PCR was performed using SYBR Premix Ex Taq, and products were detected using a
DNA Engene Opticon ${ }^{\mathrm{TM}} 2$ system (MJ Research, Waltham, MA, USA). The specific primer pairs for human BACE1, human APP, and human $\beta$-actin were designed as previously described $^{[32,38]}$ : BACE1, 5'-CATTGGAGGTATCGACCACTCGCT-3' (sense) and 5'-CCACAGTCTTCCATGTCCAAGGTG-3' (antisense); APP695, 5'-GATGGCGGTGAAGACAAAGT-3' (sense), 5'-CTTTGGCTTTCTGGAAATGG-3' (antisense) and $\beta$-actin, 5'-AGAGGGAAATCGTGCGTGAC-3' (sense), 5'-CAATAGTGATGACCTGGCCGT-3' (antisense).

PCR reaction cycles were performed as previously described using the following conditions: $95^{\circ} \mathrm{C}$ for $5 \mathrm{~s}, 58^{\circ} \mathrm{C}$ for $30 \mathrm{~s}$ and $72{ }^{\circ} \mathrm{C}$ for $20 \mathrm{~s}^{[39]}$.

\section{Statistical analysis}

All the experiments were performed at least three times. The statistical difference between multiple treatments and control was analyzed using one-way ANOVA. Data are presented as the mean \pm SEM. of three independent experiments. ${ }^{b} P<0.05$ and ${ }^{c} P<0.01$ vs control group were considered statistically significant.

\section{Results}

\section{L655,240 is a BACE1 inhibitor}

\section{L655,240 is a competitive BACE1 inhibitor in vitro}

To identify effective BACE1 inhibitors, we screened compounds from our in-house library using a FRET-based assay. Interestingly, we found that L655,240 could effectively inhibit the activity of recombinant human BACE1 in the FRET assay (Invitrogen) with an $\mathrm{IC}_{50}$ value of $4.47 \pm 1.37 \mu \mathrm{mol} / \mathrm{L}$ (Figure 2A). To further investigate the type of inhibition exhibited by L655,240 against the BACE1 enzyme, we conducted a doublereciprocal plot analysis based on the results of an enzyme kinetics assay (Figure 2B-2C). The fitted lines generated by the double reciprocal plots (Figure 2C) converged at an identical point on the $y$-axis, which indicted that L655,240 was a competitive inhibitor of BACE1.

\section{L655,240 directly binds to BACE1}

To further confirm the interaction of L655,240 with BACE1, we examined the direct binding of L655,240 to BACE1 using the SPR technology-based assay. To obtain enough BACE1 enzyme for the SPR experiment, we purified BACE1 protein from $E$ coli as previously reported ${ }^{[36]}$. We tested the enzymatic activity of BACE1 purified from $E$ coli by defining an active unit of BACE1 to be $2 \mu \mathrm{g}$. This definition is in accordance with the active unit of $1.56 \mu \mathrm{g}$ defined for BACE1 derived from insect cells used in the FRET assay kit (Invitrogen). In addition, the $\mathrm{IC}_{50}$ value of $\mathrm{L} 655,240$ for inhibition of BACE1 purified from $E$ coli was $8.10 \pm 0.09 \mu \mathrm{mol} / \mathrm{L}$ (Figure 2D), which was consistent with the $\mathrm{IC}_{50}$ value $(4.47 \pm 1.37 \mu \mathrm{mol} / \mathrm{L})$ of $\mathrm{L} 655,240$ for inhibition of BACE1 derived from insect cells.

The SPR results clearly showed that L655,240 could directly bind to BACE1 in a concentration-dependent manner. The dissociation equilibrium constant $\left(K_{\mathrm{D}}\right)$ was calculated to be 17.9 $\pm 0.72 \mu \mathrm{mol} / \mathrm{L}$ (Figure 2E). 

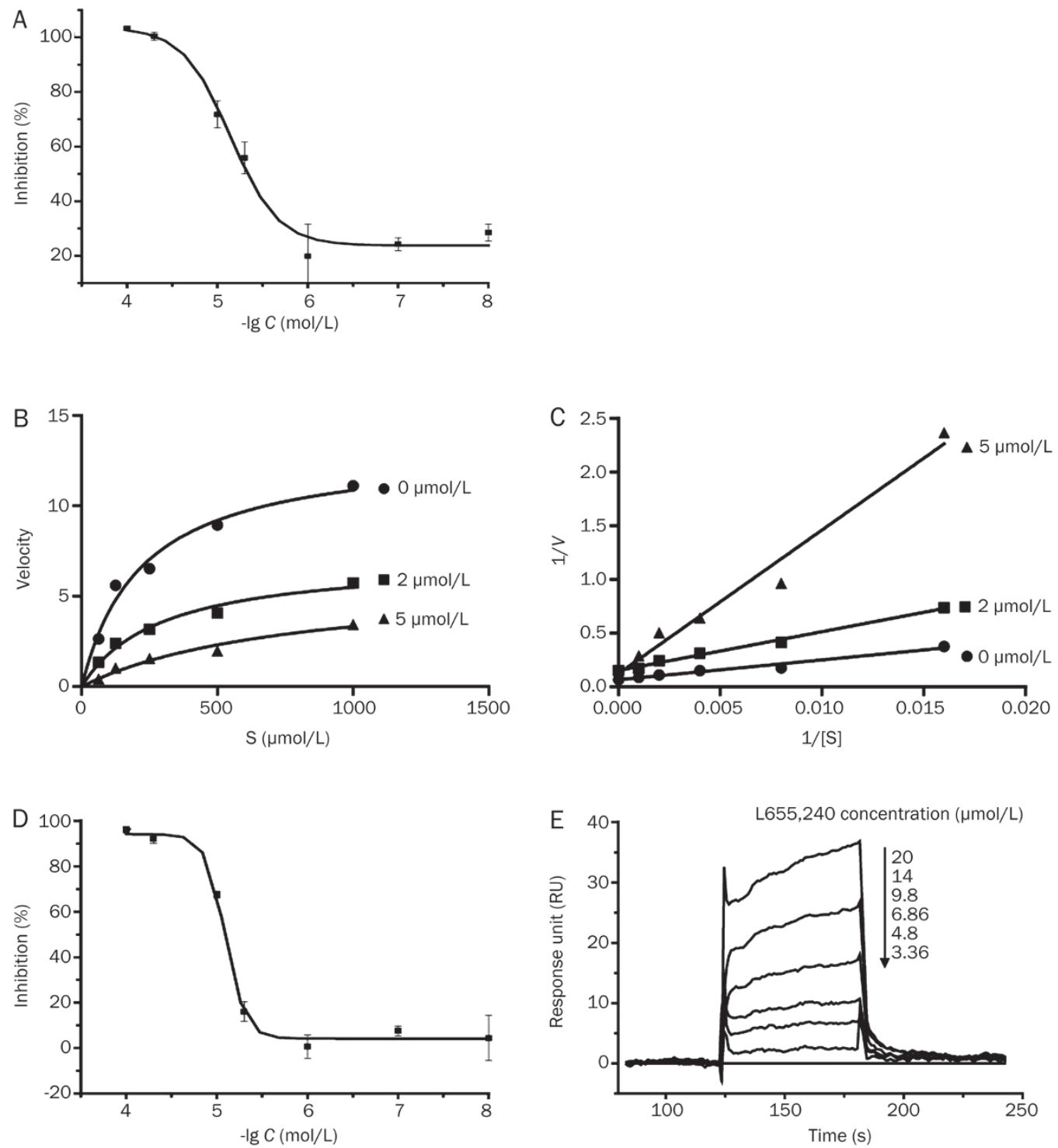

Figure 2. L655,240 is a competitive BACE1 inhibitor and directly interacts with BACE1. (A) L655,240 inhibited the activity of BACE1 isolated from insect cells with an $\mathrm{IC}_{50}$ value of $4.47 \pm 1.37 \mu \mathrm{mol} / \mathrm{L}$. (B, C) Inhibition kinetics of BACE1 by $\mathrm{L} 655,240$. Untransformed (B) and double-reciprocal plots (C) of BACE1 catalytic reactions in the presence of various concentrations of L655,240 (0, 2, and $5 \mu \mathrm{mol} / L)$. (D) L655,240 inhibited the activity of BACE1 purified from $E$ coli with an $I_{50}$ value of $8.10 \pm 0.09 \mu \mathrm{mol} / \mathrm{L}$. (E) Binding affinity of L655,240 to BACE1 was evaluated using a Biacore 3000 instrument. Sensorgrams were obtained from L655,240 injection over the immobilized BACE1 surface. Various concentrations of L655,240 were injected for $60 \mathrm{~s}$, and dissociation was monitored for more than $120 \mathrm{~s}$. Data are presented as the mean \pm SEM of three independent experiments.

\section{L655,240 exhibited no inhibitory activity against other aspartic} proteases.

To study the selectivity of L655,240 toward other aspartic proteases, we investigated the effects of various concentrations of L655,240 on the activity of renin and cathepsin D from human liver in an enzymatic assay. The results showed that L655,240 exhibited no significant inhibitory activity against renin and cathepsin D, even at concentrations of $100 \mu \mathrm{mol} / \mathrm{L}$ (Figure 3A-3B).
$L 655,240$ may decrease $A \beta 40, A \beta 42$, and SAPP $\beta$ production by directly inhibiting BACE1 activity in cells

$L 655,240$ decreased $A \beta 40, A \beta 42$, and $S A P P \beta$ production in cells

As mentioned, BACE1 is a rate-limiting enzyme in the cleavage of APP to produce $A \beta$. To further investigate the inhibitory effects of L655,240 on BACE1, we examined the effects of L655,240 on sAPP $\beta, A \beta 40$, and A $\beta 42$ production in HEK293APPswe cells. In this assay, HEK293-APPswe cells were treated with various concentrations of L655,240 or vehicle as 

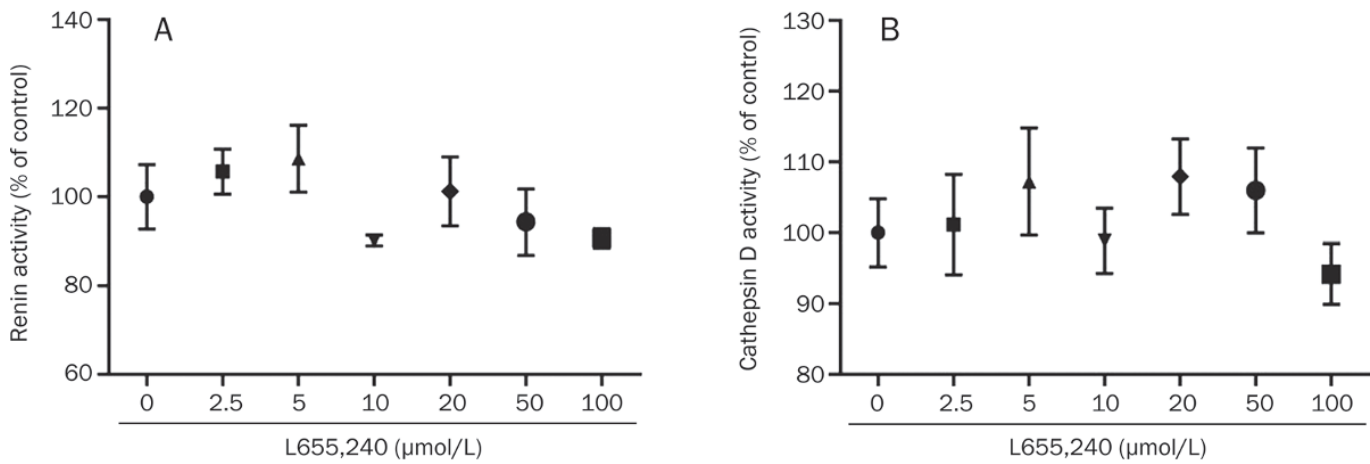

Figure 3. Selectivity of L655,240 against other aspartic proteases. (A-B) L655,240 had no effect on the activities of renin (A) and cathepsin D extracted from human liver (B). Data are presented as the mean \pm SEM of three independent experiments.

a control for $24 \mathrm{~h}$. Then, the cell culture media was directly assayed for sAPP $\beta, A \beta 40$, and $A \beta 42$. The cells were simultaneously collected and solubilized in RIPA buffer, and the cell lysates were assayed for $\mathrm{SAPP} \beta, \mathrm{A} \beta 40$, and $\mathrm{A} \beta 42$. Our results showed that L655,240 could effectively decrease sAPP $\beta, A \beta 40$ and $A \beta 42$ secretion both in cultured cell media (Figure $4 \mathrm{~A}-4 \mathrm{C}$ ) and cell lysates (Figure 4D-4E). However, we detected no A $\beta 42$ in cell lysates, which we tentatively attribute to the fact that the yield of $A \beta 42$ was too low to be detected.

Finally, to exclude the possibility that the decreased levels of sAPP $\beta, A \beta 40$, or $A \beta 42$ were caused by L655,240 induction of cell toxicity, MTT assays were conducted to evaluate cell viability. The results clearly showed that even high concentrations of L655,240 up to $50 \mu \mathrm{mol} / \mathrm{L}$ had no effect on cell viability (Figure 4F).
L655,240 exhibits no inhibitory effects against $y$-secretase or $\alpha$-secretase

To further confirm that the effects of L655,240 on decreasing $A \beta 40, A \beta 42$, and $\mathrm{SAPP} \beta$ production were mediated by modulation of BACE1 activity, cell lysates were used to assess BACE1 activity levels. The results showed that BACE1 activity in cells treated with L655,240 was significantly lower than in cells treated with vehicle (Figure 5A).

Because $\gamma$-secretase also contributes to $A \beta$ production ${ }^{[1]}$, we next investigated the potential effects of L655,240 on $\gamma$-secretase activity. As expected, L655,240 did not alter cleavage of Notch (Figure 5B), another important $\gamma$-secretase substrate $^{[40]}$ that is an important receptor for neuronal development ${ }^{[41]}$. In addition, APP can be processed along two major pathways, the a-secretase pathway and the $\beta$-secretase
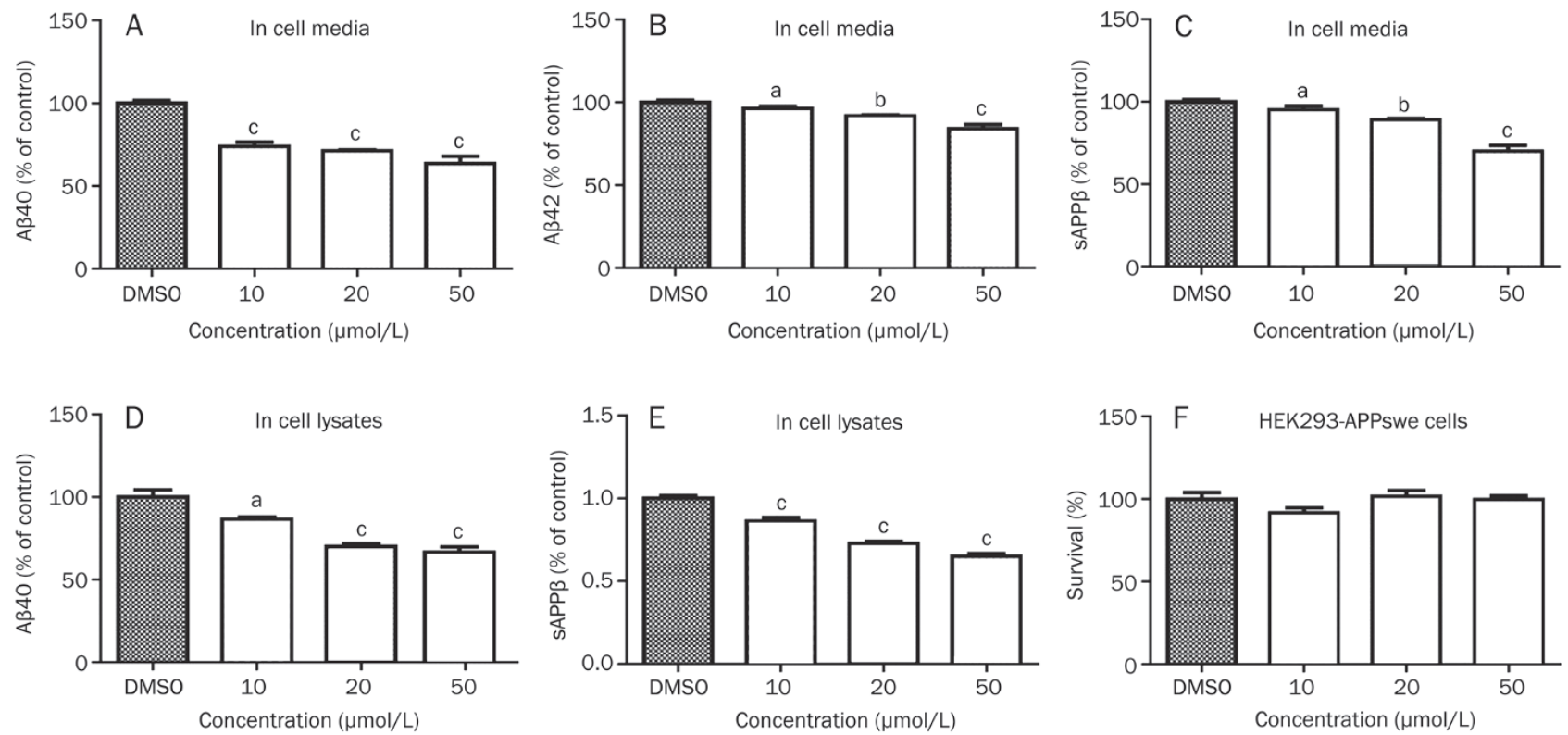

Figure 4. $L 655,240$ inhibits $A \beta 40, A B 42$, and SAPP $\beta$ production in HEK293-APPswe cells. (A-C) $L 655,240$ inhibited $A \beta 40$, $A \beta 42$, and sAPP $\beta$ secretion in media in a dose-dependent manner. (D-E) L655,240 reduced the levels of A 440 and SAPP $\beta$ in cell lysates. (F) L655,240 had no effect on cell viability as measured by MTT assay in HEK293-APPswe cells. Data are presented as the mean \pm SEM of three independent experiments. ${ }^{a} P>0.05$, ${ }^{\mathrm{b}} \mathrm{P}<0.05,{ }^{\mathrm{c}} \mathrm{P}<0.01$ vs DMSO group. 

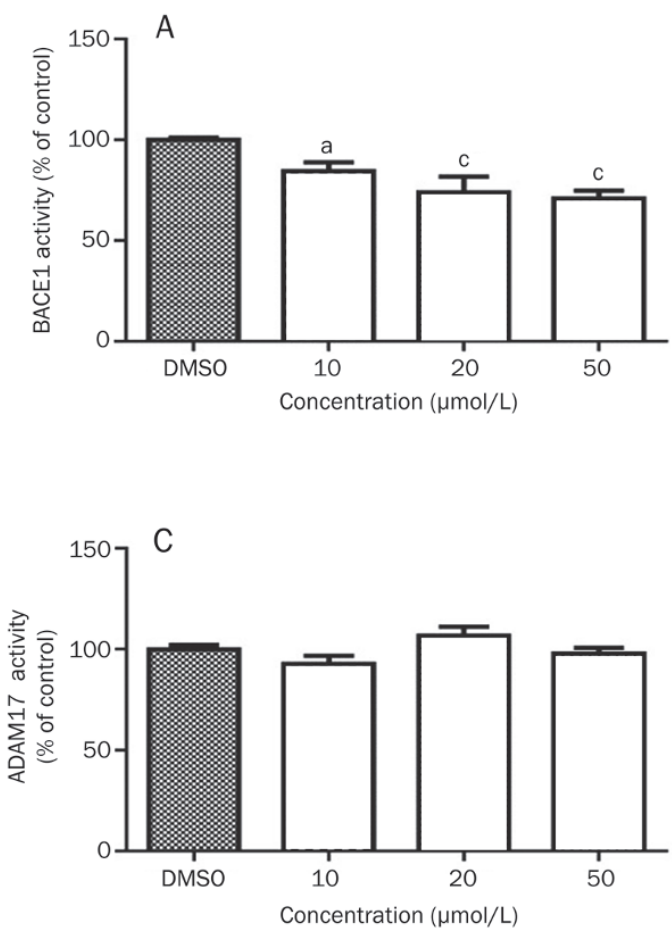

B
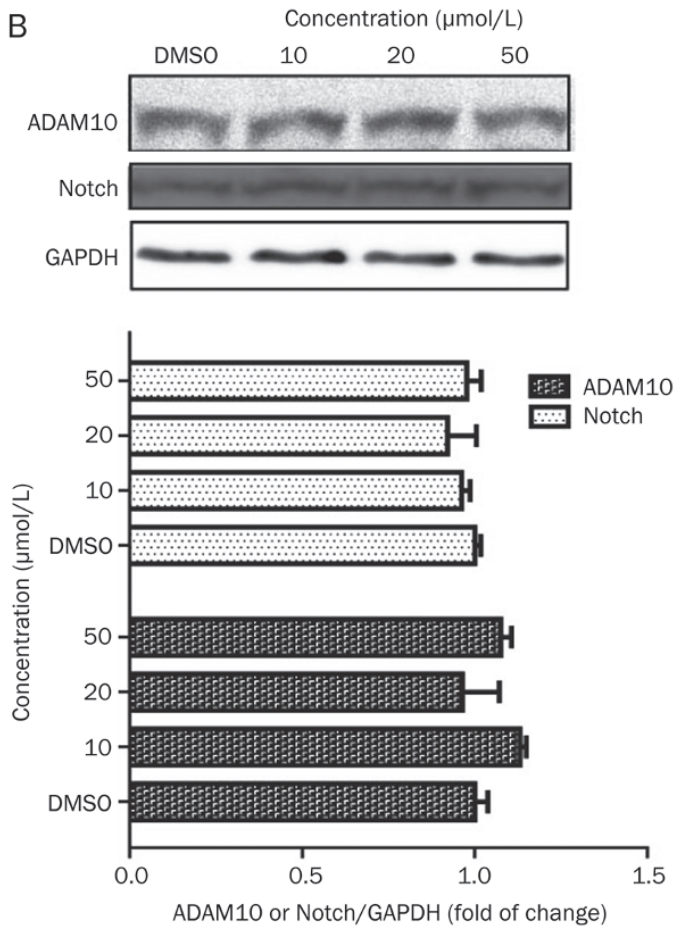

Figure 5. L655,240 inhibits the activity of BACE1 but not $\alpha$-secretase or $\gamma$-secretase. HEK293-APPswe cells were incubated with L655,240 for $24 \mathrm{~h}$ before harvesting. (A) L655,240 inhibited BACE1 activity in HEK293-APPswe cells in a concentration-dependent manner. (B) L655,240 had no effect on either $\mathrm{y}$-secretase activity or ADAM10 expression. Cell lysates were subjected to Notch and ADAM10 analysis by Western blot (upper panel); the quantitative results are also shown (lower panel). (C) L655,240 had no effect on ADAM17 activity in HEK293-APPswe cells. Data are presented as the mean \pm SEM of three independent experiments. ${ }^{a} P>0.05,{ }^{b} P<0.05,{ }^{c} P<0.01$ vs DMSO group.

pathway, which competitively cleave the same APP substrate. In the a-secretase pathway, APP is thought to be processed at the "a-site" by the ADAM family members ADAM17 and ADAM10 ${ }^{[42]}$. Here, we also investigated the effects of L655,240 on ADAM17 activity and ADAM10 expression. Our results showed that L655,240 did not affect ADAM17 activity (Figure 5C) or ADAM10 expression (Figure 5B).

\section{L655,240 has no effect on BACE1 transcript or protein levels}

As the reduction of either BACE1 activity or protein levels could decrease APP cleavage and generate SAPP $\beta$ and C99, we next examined whether L655,240 could inhibit BACE1 transcription or translation in HEK293-APPswe cells. In this assay, cells treated with different concentrations of L655,240 for $24 \mathrm{~h}$ were collected for RT-PCR analysis or Western blot analysis. As expected, the results showed that L655,240 had no effect on BACE1 protein or mRNA levels (Figure 6A, 6C).

\section{L655,240 exhibits no effect on APP transcription, protein levels} or maturation

$\mathrm{APP}$, the substrate for BACE1, plays a pivotal role in SAPP $\beta$ and $A \beta$ production. APP has both immature and mature forms in cells ${ }^{[33]}$. The mature form is generated through the post-translational modification of $\mathrm{APP}^{[44]}$ and is considered to be produced in preparation for sequential cleavage by BACE1 and $\gamma$-secretase. Therefore, we further evaluated APP mRNA levels, protein levels and APP maturation in HEK293 cells treated with L655,240 or vehicle (DMSO) as a control. The results showed that $\mathrm{L} 655,240$ had no effect on the transcription, protein levels or maturation of APP (Figure 6B, 6D).

\section{Discussion}

The Amyloid Cascade Hypothesis for AD has dominated the research field in both academia and the pharmaceutical industry since $A \beta$ was first identified as the major component of amyloid plaques in $1984^{[45]}$. The central tenet of this hypothesis is that the mismetabolism of APP is the initiating event in AD pathogenesis and subsequently leads to excessive production and deposition of $A \beta$, which is considered to be the root cause of $\mathrm{AD}^{[46,47]}$. Formation of amyloid plaques instigates further pathological events, including potential inflammatory responses, neurofibrillary tangles, disruption of synaptic connections and neuronal death, which finally results in dementia ${ }^{[48]}$. $A \beta$ is produced by sequential proteolysis of APP by BACE1 and $\gamma$-secretase. Since BACE1 is considered to be the rate-limiting enzyme for this process, the development of BACE1 inhibitors is an attractive approach to decrease $\mathrm{A} \beta$ production and deposition. However, to date, no BACE1 inhibitor has been used clinically, and the discovery of a novel BACE1 inhibitor is therefore highly significant.

Previous studies have shown that the active site of BACE1 is quite open and large ${ }^{[20]}$. Therefore, it is challenging to find 
A
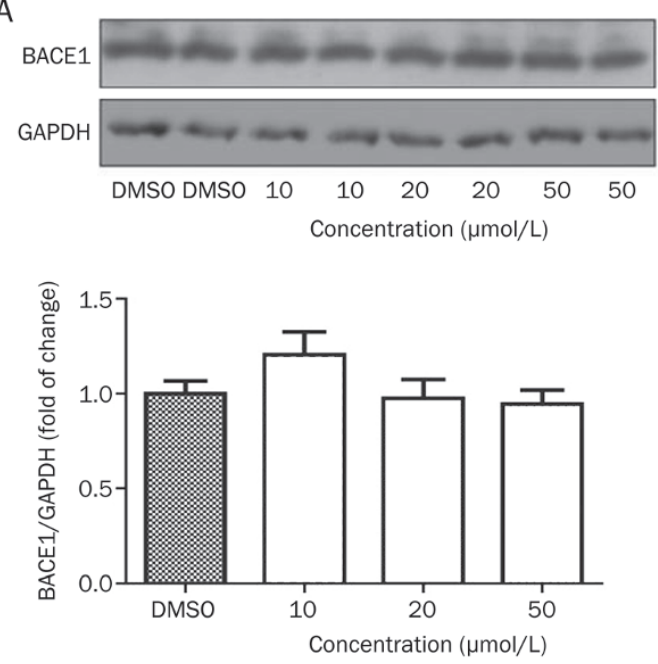

C

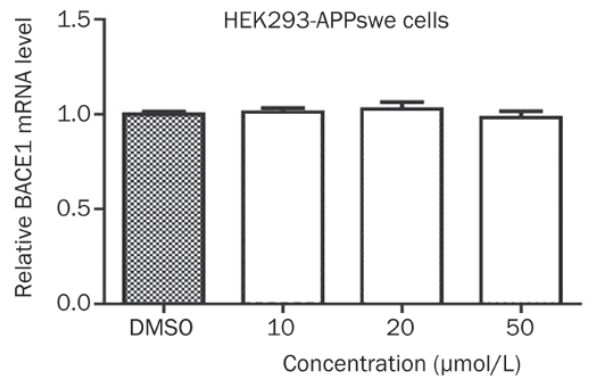

B
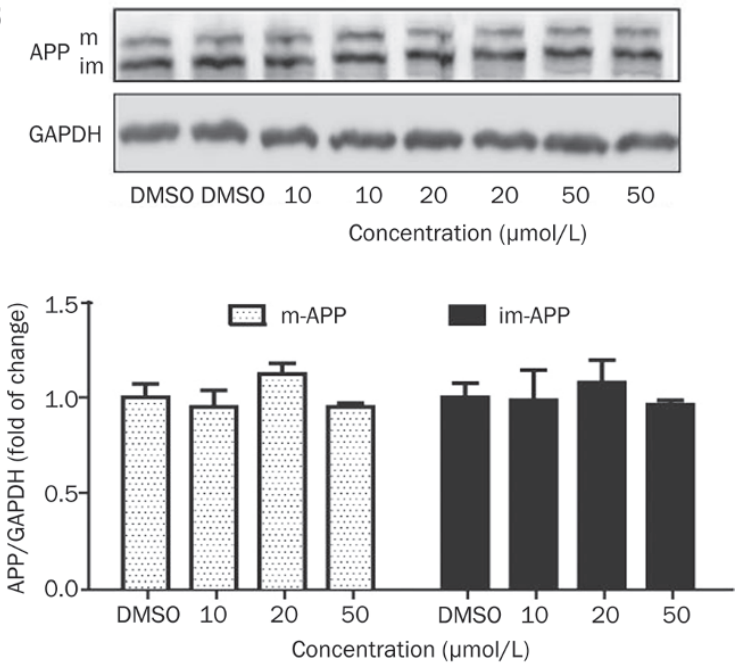

D

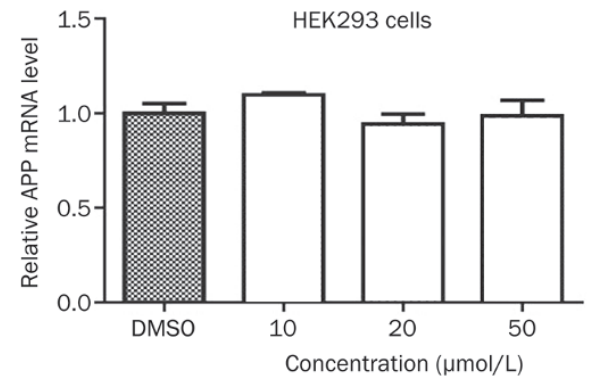

Figure 6. L655,240 had no impact on protein or mRNA levels of BACE1 or APP. All cell samples were prepared following treatment with L655,240 for $24 \mathrm{~h}$. (A) L655,240 did not affect BACE1 protein levels in HEK293-APPswe cells. Cell lysates were subjected to BACE1 analysis by Western blot (upper panel); the quantitative results are also shown below. (B) L655,240 had no effect on APP expression and maturation in HEK293 cells. Cell lysates were subjected to APP analysis by Western blot, and the quantitative results are shown below. The "im" and " $m$ " indicate the immature and mature forms of APP, respectively. (C) L655,240 did not affect the mRNA levels of BACE1 in HEK293-APPswe cells. (D) L655,240 had no effect on APP mRNA levels in HEK293 cells. Data are presented as the mean \pm SEM of three independent experiments.

potent and selective, drug-like small molecular BACE1 inhibitors. In the current study, we successfully identified a novel BACE1 inhibitor, L655,240, with a low molecular weight (373.9 $\mathrm{Da})$ that exhibited good selectivity against other aspartic proteases and displayed key characteristics of a BACE1 inhibitor including successful inhibition of $A \beta$ and $A P P \beta$ production in cell-based assays.

L655,240 has previously been reported to be a potent, orally active thromboxane antagonist that has significant effects on thromboxane receptor-mediated kidney disease and cardiovascular disease ${ }^{[33,35]}$. In this work, we reported for the first time that L655,240 could competitively inhibit recombinant human BACE1 (Figure 2A) in a dose-dependent manner (Figure 2B-2C). In addition, the affinity of L655,240 binding to BACE1 was evaluated by the SPR technology-based assay (Figure 2E).

Because BACE1 is a member of a pepsin family of aspartic proteases ${ }^{[49,50]}$ and is a type I transmembrane protein, the selectivity of L655,240 toward other aspartic proteases members was also investigated. We tested the effects of L655,240 on the activity of recombinant renin and of cathepsin $\mathrm{D}$ derived from human liver. As expected, L655,240 failed to affect the activities of either renin or cathepsin D (Figure 3A-3B).

To further confirm the biological functions of L655,240 in cells, we quantitated the levels of sAPP $\beta$, which is the direct product of BACE1 cleavage of APP, in HEK293-APPswe cells. As expected, L655,240 dramatically decreased SAPP $\beta$ production (Figure $4 \mathrm{C}$ and $4 \mathrm{E}$ ). Subsequently, we also measured the levels of $A \beta 40$ and $A \beta 42$ in cells and found that L655,240 also effectively reduced $\mathrm{A} \beta 40$ and $\mathrm{A} \beta 42$ production (Figure $4 \mathrm{~A}, 4 \mathrm{~B}$ and $4 \mathrm{D}$ ). Moreover, our results further indicated that L655,240 inhibited BACE1 activity in HEK293-APPswe cells (Figure $5 \mathrm{~A})$ without affecting mature APP and BACE1 protein levels (Figure 6A-6B). This finding confirmed that the reductions in sAPP $\beta, A \beta 40$, and $A \beta 42$ levels occurred through inhibition of BACE1 activity.

Because both $\alpha$-secretase and $\gamma$-secretase can affect $A \beta$ production, we next investigated the potential effects of L655,240 on these two secretases through analysis of a-secretase activity and Notch protein levels (the substrate of $\gamma$-secretase). As 
expected, L655,240 did not affect a-secretase activity or Notch protein levels (Figure 5B-5C). Therefore, our results further indicated that the decreases in SAPP $\beta, A \beta 40$ and $A \beta 42$ production by $\mathrm{L} 655,240$ were mediated through inhibition of BACE1 activity.

As indicated, L655,240 is an ideal BACE1 inhibitor with a small molecular size, potent BACE1 inhibitory action and good selectivity. Therefore, $\mathrm{L} 655,240$ is a potential candidate for a drug lead compound aganist AD. However, to further confirm L655,240 as a potential lead compound for the treatment of $\mathrm{AD}$, more work is needed, including investigation of L655,240 permeability through the blood brain barrier and experiments in animal models to assess the effects of L655,240 on memory impairment, both of which are beyond the scope of the current study.

In summary, our current findings demonstrate that L655,240 can effectively decrease $A \beta 40, A \beta 42$, and $A P P \beta$ production by directly inhibiting BACE1 activity. Our work has therefore provided structural information for the discovery of the drug lead compound aganist $\mathrm{AD}$ in the future.

\section{Acknowledgements}

This work was supported by the State Key Program of Basic Research of China (№ 2010CB912501), the National Natural Science Foundation of China (№ 81173105 and 30890044), the Science Foundation of Shanghai (№ 11XD1406100 and 11ZR1444500) and the Foundation of the Chinese Academy of Sciences (№ KSCX2-EW-Q-3).

\section{Author contribution}

Qin LU screened L655,240 from the compound library and performed all molecular and cellular assays in vitro; Wu-yan CHEN performed the expression and purification of BACE1; Zhi-yuan ZHU, Jing CHEN, Morakot KAEWPET, Vatcharin RUKACHAISIRIKUL, and Ye-chun XU analyzed data; $\mathrm{Xu}$ SHEN, Li-li CHEN, and Qin LU designed the experiments and wrote the manuscript. All authors discussed the results and commented on the manuscript.

\section{References}

1 Querfurth HW, LaFerla FM. Alzheimer's disease. N Engl J Med 2010; 362: 329-44.

2 Wollen KA. Alzheimer' disease: the pros and cons of phamaceutical, nutritional, botanical, and stimulatory therapies, with a discussion of treatment strategies from the perspective of patients and practitioners. Altern Med Rev 2010; 15: 223-44.

3 Hansen RA, Gartlehner G, Webb AP, Morgan LC, Moore CG, Jonas DE. Efficacy and safety of donepezil, galantamine, and rivastigmine for the treatment of Alzheimer's disease: a systematic review and metaanalysis. Clin Interv Aging 2008; 3: 211-25.

4 McShane R, Areosa Sastre A, Minakaran N. Memantine for dementia. Cochrane Database Syst Rev 2006; (2): CD003154.

5 Ohrui T, Tomita N, Sato-Nakagawa T, Matsui T, Maruyama M, Niwa K, et al. Effects of brain-penetrating ACE inhibitors on Alzheimer disease progression. Neurology 2004; 63: 1324-5.

6 Maxwell CJ, Hogan DB, Ebly EM. Calcium-channel blockers and cognitive function in elderly people: results from the Canadian Study of Health and Aging. CMAJ 1999; 161: 501-6.

7 Vlad SC, Miller DR, Kowall NW, Felson DT. Protective effects of NSAIDs on the development of Alzheimer disease. Neurology 2008; 70: $1672-7$.

8 Li X, Bo H, Zhang XC, Hartsuck JA, Tang J. Predicting memapsin 2 (beta-secretase) hydrolytic activity. Protein Sci 2010; 19: 2175-85.

9 Cole SL, Vassar R. The basic biology of BACE1: a key therapeutic target for Alzheimer's disease. Curr Genomics 2007; 8: 509-30.

10 Citron M. Beta-secretase as a target for the treatment of Alzheimer's disease. J Neurosci Res 2002; 70: 373-9.

11 Ohno M, Sametsky EA, Younkin LH, Oakley H, Younkin SG, Citron M, et al. BACE1 deficiency rescues memory deficits and cholinergic dysfunction in a mouse model of Alzheimer's disease. Neuron 2004; 41: $27-33$

12 Ohno M, Chang L, Tseng W, Oakley H, Citron M, Klein WL, et al. Temporal memory deficits in Alzheimer's mouse models: rescue by genetic deletion of BACE1. Eur J Neurosci 2006; 23: 251-60.

13 Ohno M, Cole SL, Yasvoina M, Zhao J, Citron M, Berry R, et al. BACE1 gene deletion prevents neuron loss and memory deficits in 5XFAD APP/PS1 transgenic mice. Neurobiol Dis 2007; 26: 134-45.

14 Cai H, Wang Y, McCarthy D, Wen H, Borchelt DR, Price DL, et al. BACE1 is the major beta-secretase for generation of Abeta peptides by neurons. Nat Neurosci 2001; 4: 233-4.

15 Luo Y, Bolon B, Kahn S, Bennett BD, Babu-Khan S, Denis P, et al. Mice deficient in BACE1, the Alzheimer's beta-secretase, have normal phenotype and abolished beta-amyloid generation. Nat Neurosci 2001; 4: 231-2.

16 Roberds SL, Anderson J, Basi G, Bienkowski MJ, Branstetter DG, Chen $\mathrm{KS}$, et al. BACE knockout mice are healthy despite lacking the primary beta-secretase activity in brain: implications for Alzheimer's disease therapeutics. Hum Mol Genet 2001; 10: 1317-24.

17 Wong PC, Zheng H, Chen H, Becher MW, Sirinathsinghji DJ, Trumbauer $\mathrm{ME}$, et al. Presenilin 1 is required for Notch1 and DII1 expression in the paraxial mesoderm. Nature 1997; 387: 288-92.

18 Shen J, Bronson RT, Chen DF, Xia W, Selkoe DJ, Tonegawa S. Skeletal and CNS defects in Presenilin-1-deficient mice. Cell 1997; 89: 62939.

19 Donoviel DB, Hadjantonakis AK, Ikeda M, Zheng H, Hyslop PS, Bernstein A. Mice lacking both presenilin genes exhibit early embryonic patterning defects. Genes Dev 1999; 13: 2801-10.

20 Hong L, Koelsch G, Lin X, Wu S, Terzyan S, Ghosh AK, et al. Structure of the protease domain of memapsin 2 (beta-secretase) complexed with inhibitor. Science 2000; 290: 150-3.

21 Kimura T, Shuto D, Hamada Y, Igawa N, Kasai S, Liu P, et al. Design and synthesis of highly active Alzheimer's beta-secretase (BACE1) inhibitors, KMI-420 and KMI-429, with enhanced chemical stability. Bioorg Med Chem Lett 2005; 15: 211-5.

22 Asai M, Hattori C, Iwata N, Saido TC, Sasagawa N, Szabo B, et al. The novel beta-secretase inhibitor $\mathrm{KMl}-429$ reduces amyloid beta peptide production in amyloid precursor protein transgenic and wild-type mice. J Neurochem 2006; 96: 533-40.

23 Hussain I, Hawkins J, Harrison D, Hille C, Wayne G, Cutler L, et al. Oral administration of a potent and selective non-peptidic BACE-1 inhibitor decreases beta-cleavage of amyloid precursor protein and amyloidbeta production in vivo. J Neurochem 2007; 100: 802-9.

24 Iserloh U, Pan J, Stamford AW, Kennedy ME, Zhang Q, Zhang L, et al. Discovery of an orally efficaceous 4-phenoxypyrrolidine-based BACE-1 inhibitor. Bioorg Med Chem Lett 2008; 18: 418-22.

25 Luo X, Yan R. Inhibition of BACE1 for therapeutic use in Alzheimer's disease. Int J Clin Exp Pathol 2010; 3: 618-28.

26 Cole DC, Manas ES, Stock JR, Condon JS, Jennings LD, Aulabaugh A, 
et al. Acylguanidines as small-molecule beta-secretase inhibitors. J Med Chem 2006; 49: 6158-61.

27 Baxter EW, Conway KA, Kennis L, Bischoff F, Mercken MH, Winter HL, et al. 2-Amino-3,4-dihydroquinazolines as inhibitors of BACE-1 (betasite APP cleaving enzyme): Use of structure based design to convert a micromolar hit into a nanomolar lead. J Med Chem 2007; 50: 42614.

28 Fukumoto H, Takahashi H, Tarui N, Matsui J, Tomita T, Hirode M, et al. A noncompetitive BACE1 inhibitor TAK-070 ameliorates Abeta pathology and behavioral deficits in a mouse model of Alzheimer's disease. J Neurosci 2010; 30: 11157-66.

29 Jeon SY, Bae K, Seong YH, Song KS. Green tea catechins as a BACE1 (beta-secretase) inhibitor. Bioorg Med Chem Lett 2003; 13: 3905-8.

30 Hwang EM, Ryu YB, Kim HY, Kim DG, Hong SG, Lee JH, et al. BACE1 inhibitory effects of lavandulyl flavanones from Sophora flavescens. Bioorg Med Chem 2008; 16: 6669-74.

31 Choi YH, Yoo MY, Choi CW, Cha MR, Yon GH, Kwon DY, et al. A new specific BACE-1 inhibitor from the stembark extract of Vitis vinifera. Planta Med 2009; 75: 537-40.

32 Zhu Z, Li C, Wang X, Yang Z, Chen J, Hu L, et al. 2,2',4'-trihydroxychalcone from Glycyrrhiza glabra as a new specific BACE1 inhibitor efficiently ameliorates memory impairment in mice. J Neurochem 2009; 114: 374-85.

33 Hall RA, Gillard J, Guindon Y, Letts G, Champion E, Ethier D, et al. Pharmacology of L-655,240 (3-[1-(4-chlorobenzyl)-5-fluoro-3-methylindol-2-yl]2,2-dimethylpro pan oic acid); a potent, selective thromboxane/prostaglandin endoperoxide antagonist. Eur J Pharmacol 1987; 135: 193-201.

34 Conroy DM, Sirois P. Early bronchial hyperresponsiveness following injection of sephadex beads in the guinea pig: involvement of platelet activating factor and thromboxane $A_{2}$. Inflammation 1999; 23: 43748.

35 Wainwright CL, Parratt JR. The effects of L655,240, a selective thromboxane and prostaglandin endoperoxide antagonist, on ischemia- and reperfusion-induced cardiac arrhythmias. J Cardiovasc Pharmacol 1988; 12: 264-71.

36 Xu Y, Li MJ, Greenblatt H, Chen W, Paz A, Dym O, et al. Flexibility of the flap in the active site of BACE1 as revealed by crystal structures and molecular dynamics simulations. Acta Crystallogr D Biol Crystallogr 2011; 68: 13-25.

37 Liu Q, Zhang Y, Lin Z, Shen H, Chen L, Hu L, et al. Danshen extract 15,16-dihydrotanshinone I functions as a potential modulator against metabolic syndrome through multi-target pathways. J Steroid
Biochem Mol Biol 2010; 120: 155-63.

38 Cachard-Chastel M, Lezoualc'h F, Dewachter I, Delomenie C, Croes S, Devijver $\mathrm{H}$, et al. $5-\mathrm{HT}_{4}$ receptor agonists increase sAPPalpha levels in the cortex and hippocampus of male C57BL/6j mice. Br J Pharmacol 2007; 150: 883-92.

39 Wang L, Wang X, Chen J, Yang Z, Yu L, Hu L, et al. Activation of protein serine/threonine phosphatase PP2Calpha efficiently prevents liver fibrosis. PLoS One 2010; 5: e14230.

40 Kopan R, Goate A. A common enzyme connects notch signaling and Alzheimer's disease. Genes Dev 2000; 14: 2799-806.

41 Louvi A, Artavanis-Tsakonas S. Notch signalling in vertebrate neural development. Nat Rev Neurosci 2006; 7: 93-102.

42 Allinson TM, Parkin ET, Turner AJ, Hooper NM. ADAMs family members as amyloid precursor protein alpha-secretases. J Neurosci Res 2003; 74: 342-52.

43 Weidemann A, Konig G, Bunke D, Fischer P, Salbaum JM, Masters $\mathrm{CL}$, et al. Identification, biogenesis, and localization of precursors of Alzheimer's disease A4 amyloid protein. Cell 1989; 57: 115-26.

44 Tomita S, Kirino Y, Suzuki T. Cleavage of Alzheimer's amyloid precursor protein (APP) by secretases occurs after 0-glycosylation of APP in the protein secretory pathway. Identification of intracellular compartments in which APP cleavage occurs without using toxic agents that interfere with protein metabolism. J Biol Chem 1998; 273: 6277-84.

45 Glenner GG, Wong CW. Alzheimer's disease: initial report of the purification and characterization of a novel cerebrovascular amyloid protein. Biochem Biophys Res Commun 1984; 120: 885-90.

46 Tanzi RE, Bertram L. Twenty years of the Alzheimer's disease amyloid hypothesis: a genetic perspective. Cell 2005; 120: 545-55.

47 Karran E, Mercken M, De Strooper B. The amyloid cascade hypothesis for Alzheimer's disease: an appraisal for the development of therapeutics. Nat Rev Drug Discov 2011; 10: 698-712.

48 Hardy J, Allsop D. Amyloid deposition as the central event in the aetiology of Alzheimer's disease. Trends Pharmacol Sci 1991; 12: 383-8.

49 Hussain I, Powell D, Howlett DR, Tew DG, Meek TD, Chapman C, et al. Identification of a novel aspartic protease (Asp 2) as beta-secretase. Mol Cell Neurosci 1999; 14: 419-27.

50 Citron M, Westaway D, Xia W, Carlson G, Diehl T, Levesque G, et al. Mutant presenilins of Alzheimer's disease increase production of 42-residue amyloid beta-protein in both transfected cells and transgenic mice. Nat Med 1997; 3: 67-72. 